\title{
El diagnóstico prenatal de síndrome de Down podría realizarse analizando la sangre materna
}

Down syndrome may be diagnosed in the prenatal period based on a maternal blood test

Dhallan R. Lancet. 2007 Feb 10;369(9560):474-81

\begin{abstract}
Objetivo
Establecer si los polimorfismos de nucleótidos únicos (PNU y en inglés SNP) pueden ser usados para distinguir el ADN fetal del materno y así determinar el número de cromosomas fetales en muestras de sangre materna.
\end{abstract}

\section{Diseño}

Estudio prospectivo de cohorte.

\section{Lugar}

Red de diez centros de diagnóstico perinatal, Columbia, EEUU.

\section{Pacientes}

60 embarazos seguidos hasta el nacimiento

\section{Descripción de los tests y del test de referencia} obtenido por amniocentesis o por evaluación del recién nacido. Se obtuvieron muestras de sangre materna y paterna y se analizaron en forma ciega por el laboratorio central. Ver cuadro 1.

\section{Cuadro 1: definición de polimorfismo de nucleótidos únicos.}

En la sangre de la embarazada circula ADN fetal producto de la apoptosis de células del embarazo. Existen variaciones del genoma entre los individuos, denominadas polimorfismos de nucleótidos únicos (PNU). Si en un sitio del genoma la madre es homocigota para un nucleótido, por ejemplo guanina $(G / G)$ y el padre es homocigota para otro nucleótido (por ej. T/T) el
Todas las pruebas se compararon con el cariotipo prenatal

feto será heterocigota $\mathrm{G} / \mathrm{T}$. El uso de múltiples PNU permitiría detectar en la sangre materna alelos de origen fetal, y mediante el cociente entre el número de alelos fetales y maternos, evaluar el número de cromosomas fetales.

\section{Medición de Resultados Principales}

La mediana de edad materna fue 34 años y la de edad gestacional 17 semanas y 5 días (rango: 8 a 38 sem.). La proporción promedio de ADN fetal fue de $34,0 \%$ (mediana $32,5 \%$ y rango 17,0 a 93,8 ). En la muestra de 60 casos hubo 57 recién nacidos normales y tres embarazos con trisomía 21. El método identificó correctamente a 56 de los 57 embarazos no afectados, y detectó dos de los tres casos de trisomía 21 con una sensibilidad de $66,7 \%$ (IC95\%: 12,5 a 98,2 ) y una especificidad de $98,2 \%(89,4$ a 99,9$)$ un valor predictivo positivo de $66,7 \%$ $(12,5$ a 98,2$)$ y un valor predictivo negativo de $98,2 \%(89,4$ a $99,9)$.

\section{Conclusiones}

Los resultados muestran que, a través del estudio de muestras de sangre materna, el uso de PNU puede distinguir el ADN fetal del materno y por lo tanto el número de cromosomas fetales. Mediante mayores refinamientos, este método podría ser un complemento útil a las pruebas de diagnóstico prenatal que se usan actualmente.

Palabras clave: anormalidades cromosómicas, diagnóstico prenatal, ADN fetal, suero materno, polimorfismo de nucleótidos únicos.

Key words: chromosome abnormalities, prenatal diagnosis, fetal DNA, maternal serum, single nucleotide polymorphisms. Fuente de financiamiento: Laboratorio Ravgen, del cual Ravinder Dhallan es el fundador, jefe ejecutivo y presidente del

\section{Comentario}

La translucencia nucal por ecografía y las mediciones bioquímicas en la sangre materna como rastreo prenatal permiten elegir mejor qué embarazos serían beneficiados con estudios diagnósticos más precisos como la amniocentesis o la aspiración de vellosidades coriónicas. Este rastreo prenatal hoy tiene una sensibilidad de $85 \%$ a $95 \%$, con una tasa de falsos positivos que no superan el 1 al $5 \%$, dependiendo del método usado ${ }^{1-2}$. La presencia de ADN fetal en la circulación materna ha abierto nuevas rutas de investigación para el diagnóstico prenatal ${ }^{3-4}$, pero hasta ahora ha sido difícil identificar el número de cromosomas fetales en la sangre materna, ya que ésta es una muestra heterogénea de ADN fetal y materno. El uso de múltiples PNU permitiría detectar y cuantificar alelos fetales heredados del padre y mediante el cociente entre los alelos fetales y los alelos maternos, establecer el número de cromosomas fetales. En este estudio todas las pruebas fueron hechas en forma ciega e independiente de los test de diagnósticos prenatal y los resultados no influyeron en el manejo clínico. No obstante, la cifra de sensibilidad y especificidad reportada por los autores no es superior a la de los métodos actuales

de rastreo, y el escaso número de pacientes -lo que implica que haya habido sólo tres casos- implica un intervalo de confianza muy amplio. Además, la población del estudio está seleccionada ya que la mediana de edad materna es de 34 años, lo que eleva artificialmente el valor predictivo positivo de la prueba, por lo que sería necesario replicar el método con un número mayor casos y en la población general. Por otra parte, si bien el método propuesto requiere el uso de equipamiento estándar de biología molecular, esta tecnología es aún muy costosa en nuestro medio.

\section{Conclusiones del comentador}

Es posible que a pesar de las limitaciones actuales, el análisis del ADN fetal en circulación materna sea en el futuro una de las herramientas más importantes de diagnóstico prenatal, y aunque los procedimientos invasivos no sean totalmente reemplazados, estas técnicas en sangre materna se incorporen al actual arsenal bioquímico y ecográfico ${ }^{5}$ como métodos de rastreo altamente eficientes.

Horacio Aiello [ Sección de Medicina Fetal, Servicio de Obstetricia, Hospital Italiano de Buenos Aires. ]

Aiello H. El diagnóstico prenatal de trisomía del par 21 podría realizarse analizando cromosomas fetales presentes en la sangre materna. Evid. actual. práct. ambul; 10(4): 110, Jul-Ago 2007. Comentado de: Dhallan R, Guo X, Emche S, Damewood M, Bayliss P, Cronin M, Barry J, Betz J, Franz K Gold K, Vallecillo B, Varney J. A non-invasive test for prenatal diagnosis based on fetal DNA present in maternal blood: a preliminary study. Lancet. 2007 Feb 10;369(9560):474-81. PMID: 17292767.

Bibliografía

1. Malone FD, Canick JA, Ball RH, et al. First-trimester or second-trimester screening, or both, for Down's syndrome. N Engl J Med 2005; 353: 2001-11.

2. Nicolaides KH. Nuchal translucency and other first-trimester sonographic markers of chromosomal abnormalities. Am J Obstet Gynecol 2004;191: 45-67.

3. Lo YM, Tein MSC, Lau TK, et al. Quantitative analysis of fetal DNA in maternal plasma and serum: implications for noninvasive prenatal diagnosis. Am J Hum Genet 1998; 62: $768-75$.

4. Chim SS, Tong YK, Chiu RW, et al. Detection of the placental epigenetic signature of the maspin gene in maternal plasma. Proc Natl Acad Sci U S A. 2005 Oct 11;102(41):14753-8. Epub 2005 Oct 3.

5. Anon. ACOG practice bulletin no. 77: screening for fetal chromosomal abnormalities. Obstet Gynecol 2007; 109: 217-27. 